\title{
Electrochemical analysis of nanostructured iron oxides using cyclic voltammetry and scanning electrochemical microscopy
}

\section{Heinz Bülter}

heinz.buelter@uni-oldenburg.de

Guy Denuaulta, b, 1

gd@soton.ac.uk

Stefan Mátéfi-Tempfli ${ }^{\mathrm{a},}$

stefan.matefi-tempfli@th-deg.de

Mária Mátéfi-Tempfli

matefi_tempfli@lycos.com

Carsten Dosche ${ }^{\mathrm{a}, \mathrm{b}, \mathrm{e}}$

carsten.dosche@uni-oldenburg.de

Gunther Wittstock ${ }^{\mathrm{a}, *, 1}$

gunther.wittstock@uni-oldenburg.de

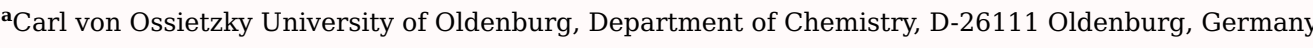

bUniversity of Southampton, Department of Chemistry, Highfield, Southampton, SO17 1BJ, UK

'Deggendorf Institute of Technology, Faculty of Natural Sciences and Industrial Engineering, European Campus Rottal-Inn, 84347 Pfarrkirchen, Germany

${ }^{*}$ Corresponding author

${ }^{1}$ ISE member

\section{Abstract}

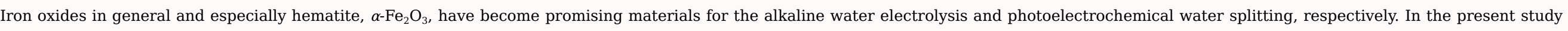

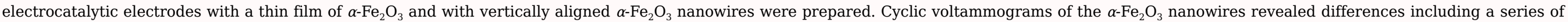

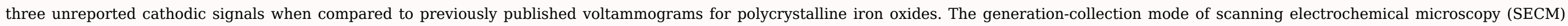

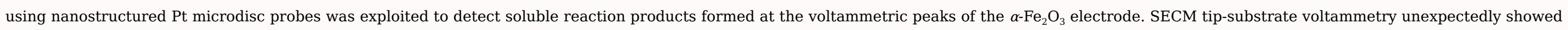
that the reduction of $\mathrm{Fe}^{\mathrm{VI}}$ to $\mathrm{Fe}^{\mathrm{III}}$ on the cathodic sweep is accompanied by significant $\mathrm{O}_{2}$ evolution.

Keywords: scanning electrochemical microscopy; nanostructured hematite electrodes; oxygen evolution reaction; alkaline water electrolysis

\section{Introduction}

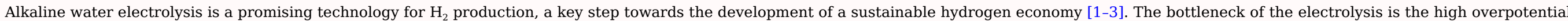

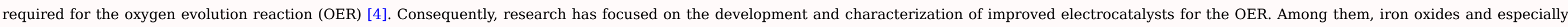

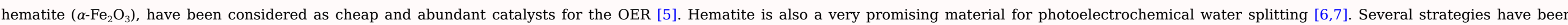




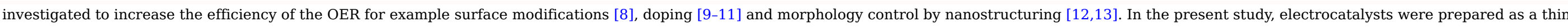
film of $\alpha$ - $\mathrm{Fe}_{2} \mathrm{O}_{3}$ and as vertically aligned $\alpha$ - $\mathrm{Fe}_{2} \mathrm{O}_{3}$ nanowires.

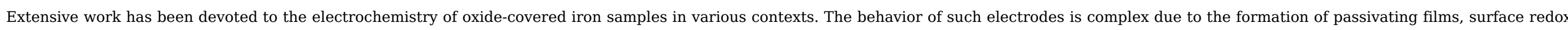

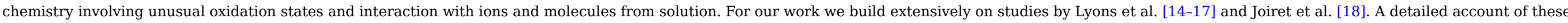
studies is given in the result and discussion section and is summarized in Table 1.

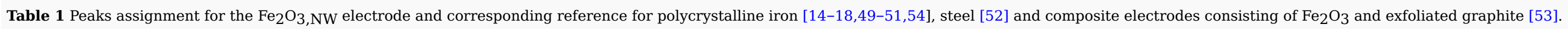
alt-text: Table 1

\begin{tabular}{|c|c|c|c|c|}
\hline Peak & $E_{\mathrm{S}} / \mathrm{Va}$ & Reported in Refs. & Assignment & Ref. for Assignm. \\
\hline $\mathbf{A 1}$ & -1.19 & {$[14-16,18,50,51,53]$} & $\begin{array}{l}\mathrm{Fe}^{\mathrm{I}} \mathrm{OH}+\mathrm{OH}^{-} \rightarrow \mathrm{Fe}^{\mathrm{II}}(\mathrm{OH})_{2}+\mathrm{e}^{-}(1) \\
\text { or } \\
\mathrm{Fe}^{\mathrm{I} O H}+\mathrm{OH}^{-} \rightarrow \mathrm{Fe}^{\mathrm{II}} \mathrm{O}+\mathrm{H}_{2} \mathrm{O}+\mathrm{e}^{-}(2)\end{array}$ & {$[14]$} \\
\hline A2 & -1.07 & {$[14-18,49,51-53]$} & $\mathrm{Fe}^{\mathrm{II}}(\mathrm{OH})_{2}+\mathrm{OH}^{-} \rightarrow \mathrm{Fe} \mathrm{FII}^{\mathrm{II}} \mathrm{OOH}+\mathrm{H}_{2} \mathrm{O}+\mathrm{e}^{-}(3)$ & [17] \\
\hline $\mathbf{A 3}$ & +0.15 & {$[16,18,54]$} & $\mathrm{Fe}^{\mathrm{III} O O H}+3 \mathrm{OH}^{-} \rightarrow \mathrm{Fe}^{\mathrm{VII}_{3}}+3 \mathrm{e}^{-}+2 \mathrm{H}_{2} \mathrm{O}(4)$ & {$[54]$} \\
\hline C1 & -1.21 & {$[16,18,52,53]$} & $\begin{array}{l}3 \gamma-\mathrm{Fe}_{2}^{\mathrm{III}} \mathrm{O}_{3}+\mathrm{H}_{2} \mathrm{O}+2 \mathrm{e}^{-} \rightarrow 2 \mathrm{Fe}^{\mathrm{III} / \mathrm{II}} \mathrm{O}_{4}+2 \mathrm{OH}^{-}(5) \\
3 \alpha-\mathrm{Fe}^{\mathrm{III}} \mathrm{OOH}+\mathrm{e}^{-} \rightarrow \mathrm{Fe}^{\mathrm{III} / \mathrm{II}} \mathrm{O}_{4}+\mathrm{H}_{2} \mathrm{O}+\mathrm{OH}^{-}(6)\end{array}$ & [18] \\
\hline $\mathbf{C 2}$ & -0.91 & not reported & & \\
\hline $\mathbf{C 3}$ & -0.58 & not reported & & \\
\hline $\mathbf{C 4}$ & -0.37 & {$[16,18,54]$} & $\mathrm{Fe}^{\mathrm{VII}_{3}}+3 \mathrm{e}^{-}+2 \mathrm{H}_{2} \mathrm{O} \rightarrow \mathrm{Fe}^{\mathrm{III} O O H}+3 \mathrm{OH}^{-}(7)$ & [54] \\
\hline $\mathbf{C 5}$ & +0.22 & not reported & & \\
\hline
\end{tabular}

a vs. SMSE as measured in this paper. Exact potential values vary between different reports.

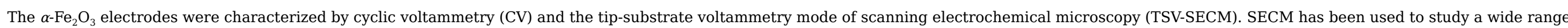

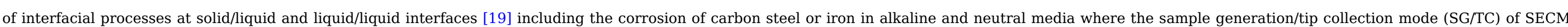

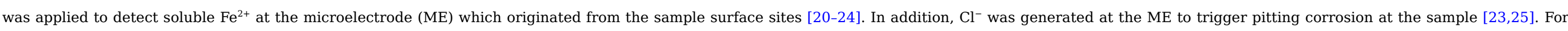

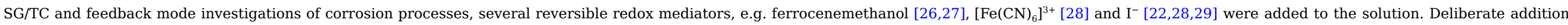

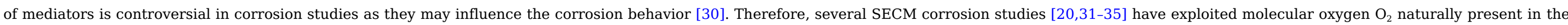

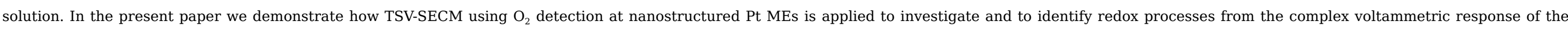

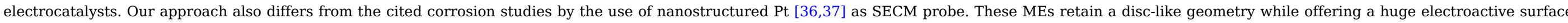

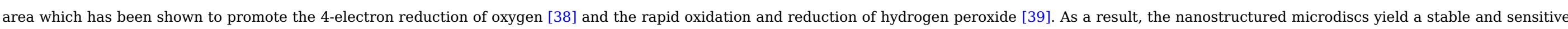

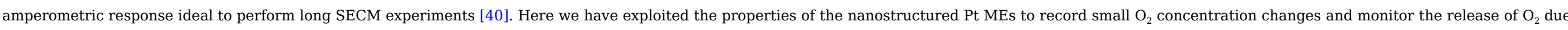
to surface redox processes at $\alpha$ - $\mathrm{Fe}_{2} \mathrm{O}_{3}$ nanowires.

\section{Experimental}

\subsection{Template and sample preparation}

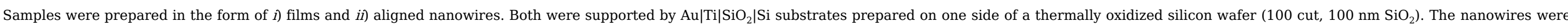




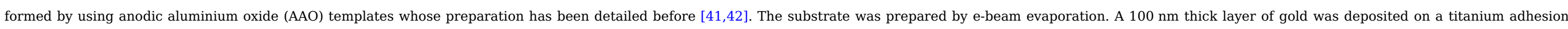

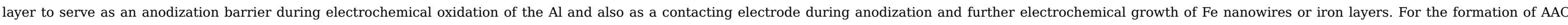

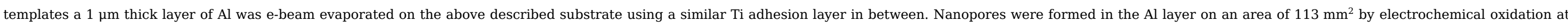

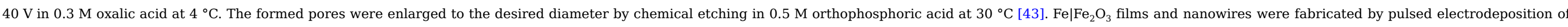

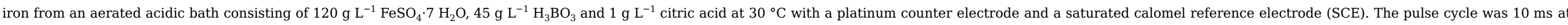

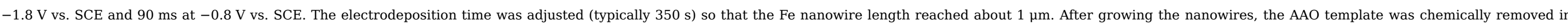

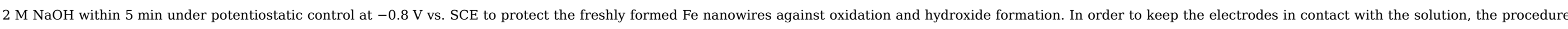

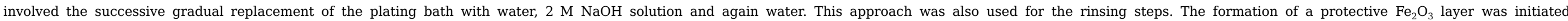

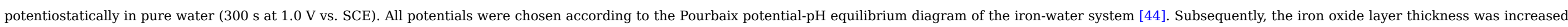
to its final value by thermal oxidation in air at $300^{\circ} \mathrm{C}$.

\subsection{Scanning electrochemical microscopy and cyclic voltammetry}

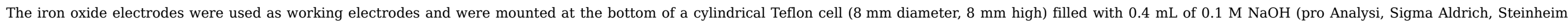

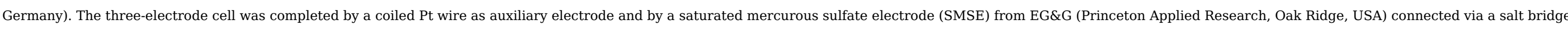
to the cell. All potentials are referenced to the SMSE. The experiments were conducted in a grounded and closed Faraday cage in the dark.

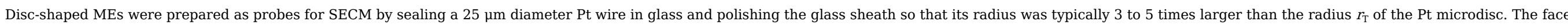

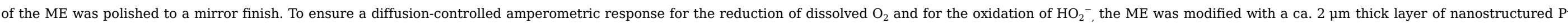

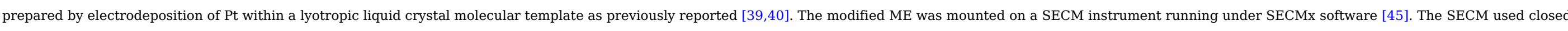

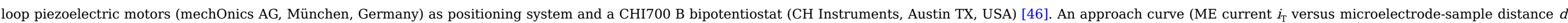

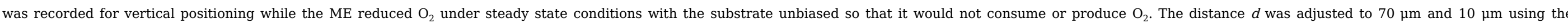

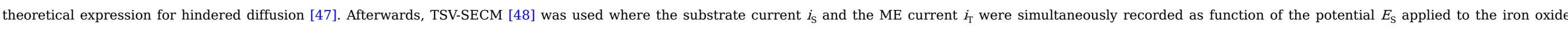

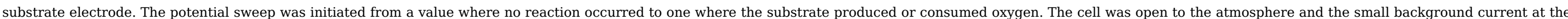
ME due to the reduction of $\mathrm{O}_{2}$ from the air-saturated electrolyte solution was used as a reference value.

\subsection{Scanning electron microscopy}

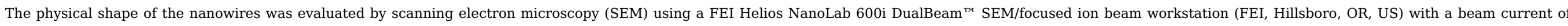

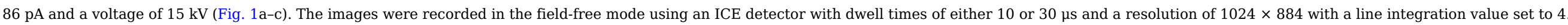




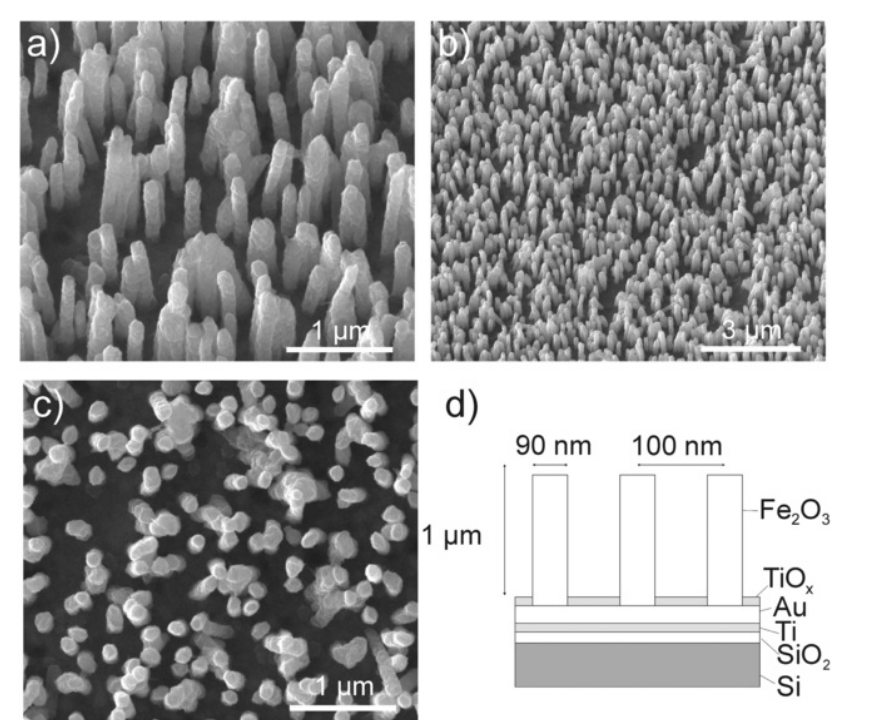

Fig. 1 Dimensions of the iron oxide nanowires $\left(\mathrm{Fe}_{2} \mathrm{O}_{3, \mathrm{NW}}\right)$ in a typical SEM micrographs of an array of nanowires tilted by $30^{\circ}$, (a and b), in top view (c) and as schematic (d).

alt-text: Fig. 1

\section{Results and discussion}

\subsection{Structure of $\alpha-\mathrm{Fe}_{2} \mathrm{O}_{3}$ samples}

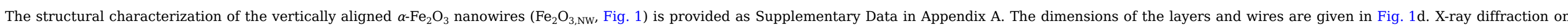

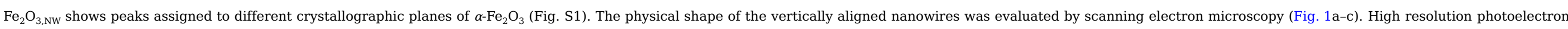
spectra confirm that assignment (Fig. S2).

\subsection{Voltammetric response}

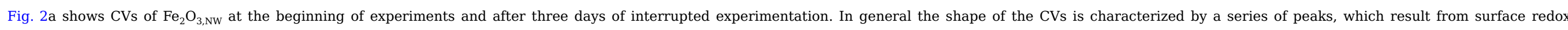

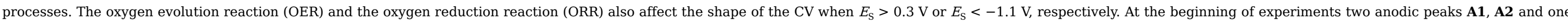

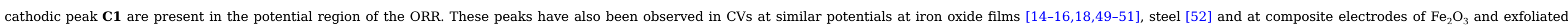
graphite [53]. Their assignment to specific reactions is summarized in Table 1. 

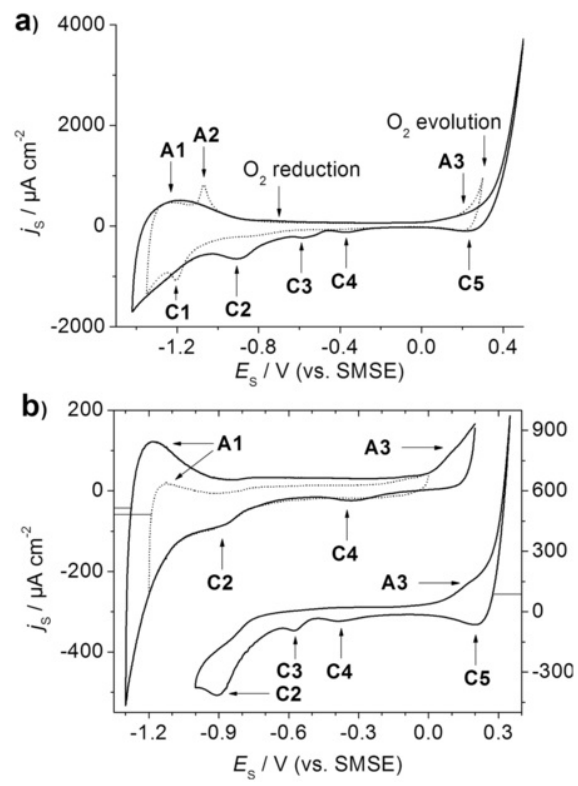

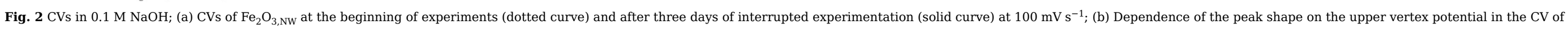
$\mathrm{Fe}_{2} \mathrm{O}_{3, \mathrm{NW}}$ at $50 \mathrm{mV} \mathrm{s}^{-1}$ : The peaks $\mathbf{C 4}$ and $\mathbf{A} \mathbf{3}$ appear when the upper vertex potential is above $E_{\lambda}>0.0 \mathrm{~V}$ vs. SMSE while $\mathbf{C} 3$ and $\mathbf{C 5}$ appear when $E_{\lambda}>0.3 \mathrm{~V}$ vs. SMSE.

alt-text: Fig. 2

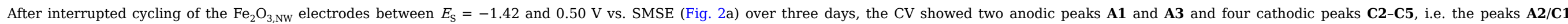

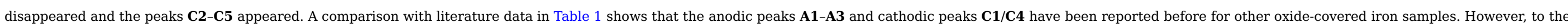
best of our knowledge, the peaks $\mathbf{C 2}, \mathbf{C 3}$ and $\mathbf{C 5}$ have not been reported for polycrystalline iron oxide.

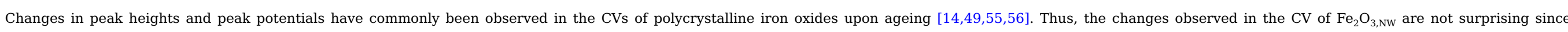

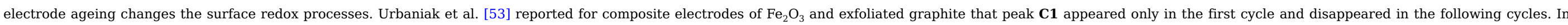

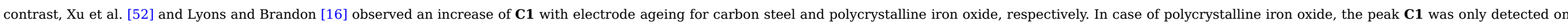

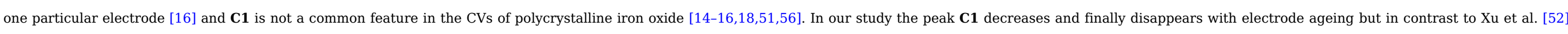
the peak $\mathbf{C 1}$ is seen over many cycles (Fig. 2a). Thus, $\mathrm{Fe}_{2} \mathrm{O}_{3, \mathrm{NW}}$ shows a particular behavior with respect to the peak $\mathbf{C 1}$.

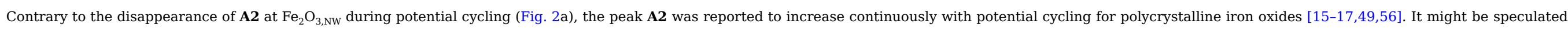

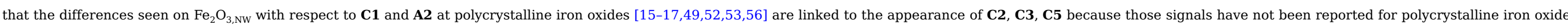
electrodes.

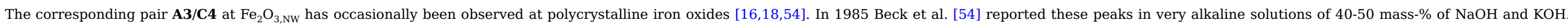

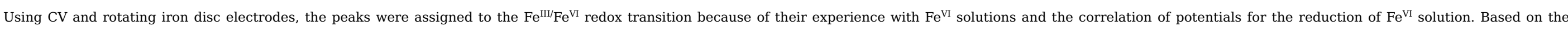

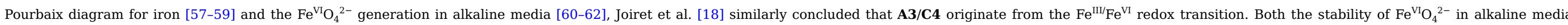

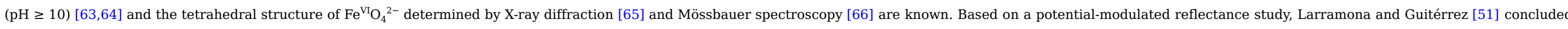

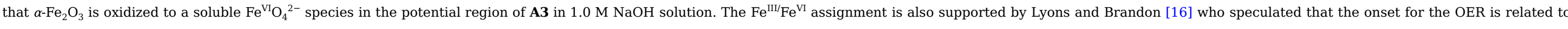

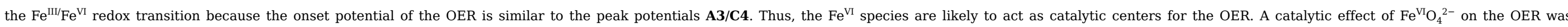

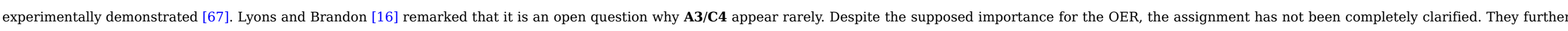




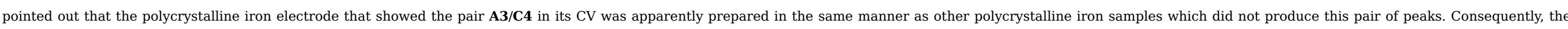

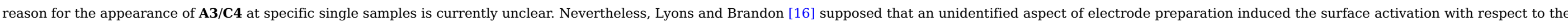

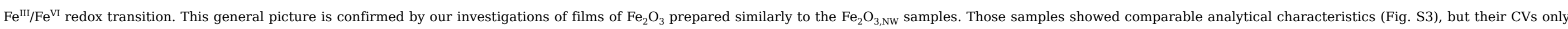

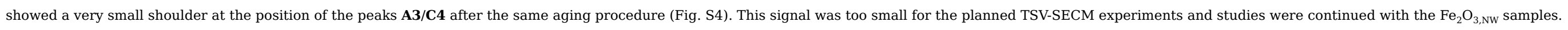

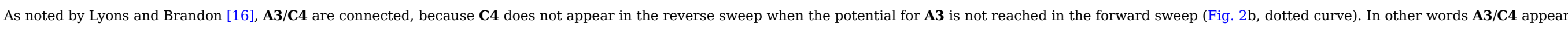

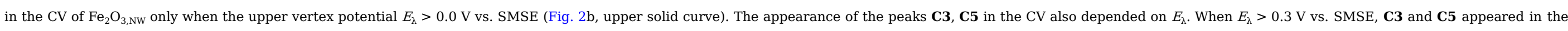
$\mathrm{CV}$ (Fig. 2b, lower solid curve). In contrast to $\mathbf{C 3}, \mathbf{C 4}$ and $\mathbf{C 5}$, the peak $\mathbf{C 2}$ was present in the CV even for $E_{\lambda}=0.0 \mathrm{~V}$ vs. SMSE (Fig. 2b, dotted curve).

\subsection{Peak assignment using TSV-SECM}

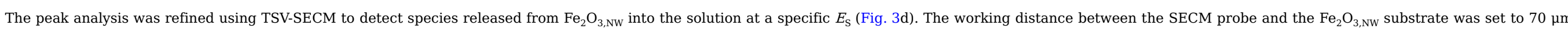

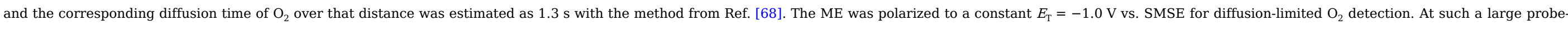

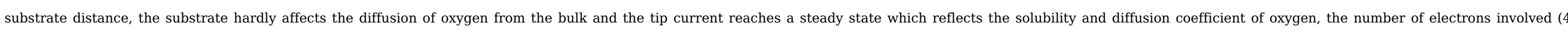

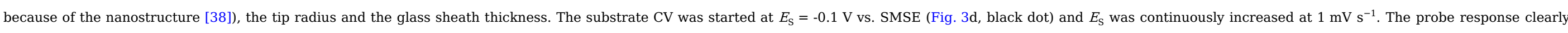

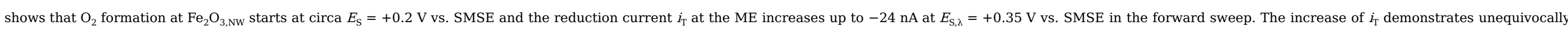

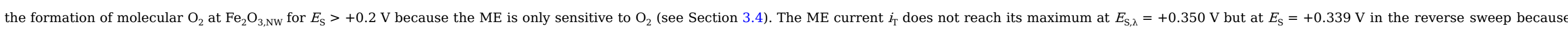

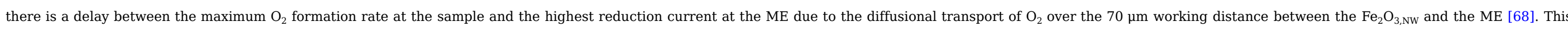

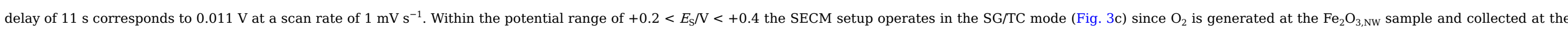

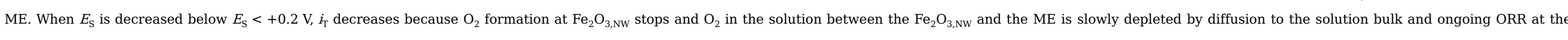

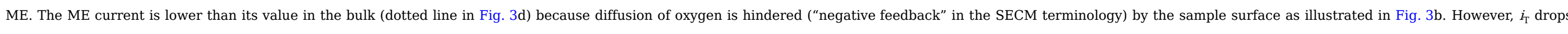

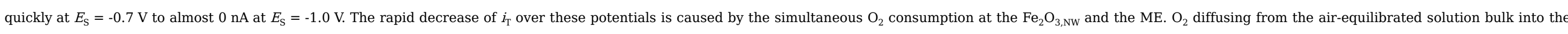

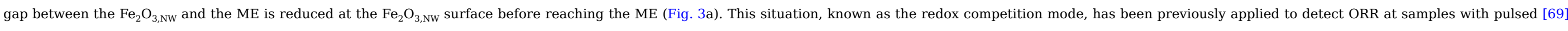

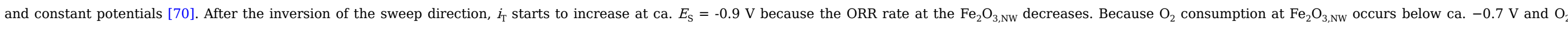

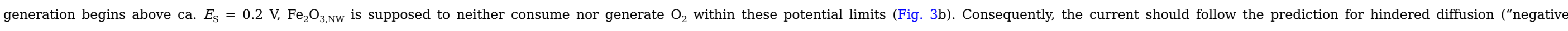

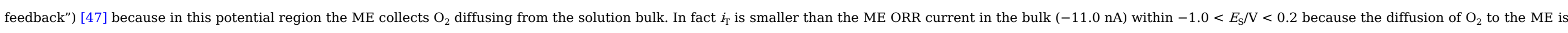
slightly hindered by the $\mathrm{Fe}_{2} \mathrm{O}_{3, \mathrm{NW}}$ surface at $d=70 \mu \mathrm{m}$ and because $\mathrm{O}_{2}$ was depleted by ORR at the $\mathrm{Fe}_{2} \mathrm{O}_{3, \mathrm{NW}}$ sample in the preceding cycle. 


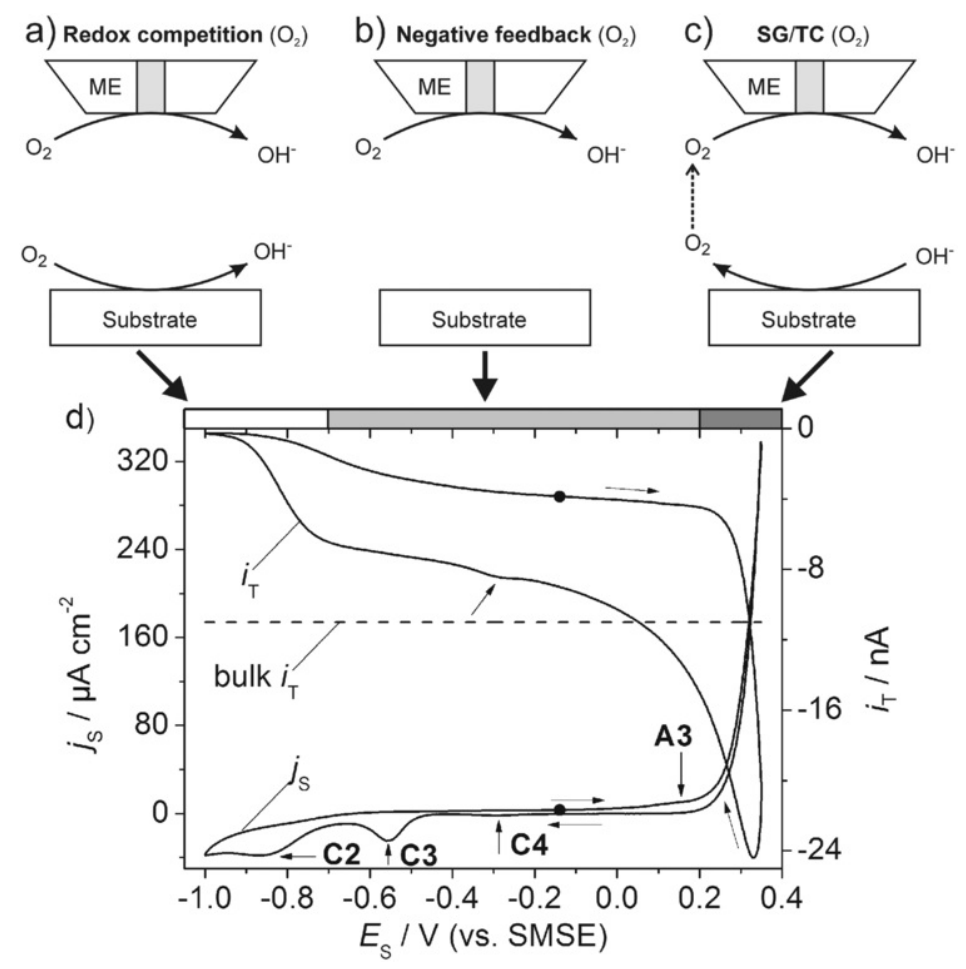

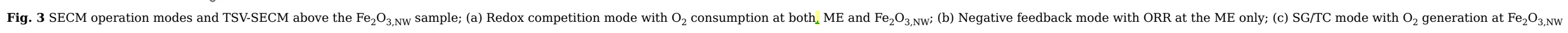

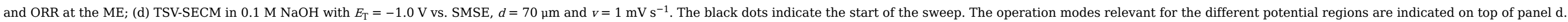

\section{alt-text: Fig. 3}

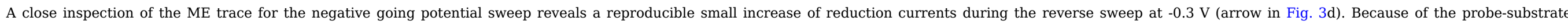

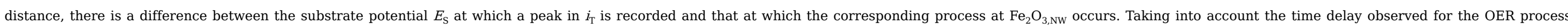

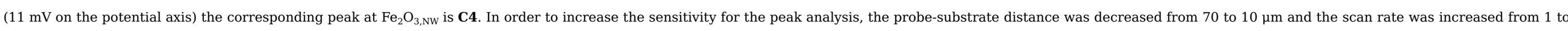

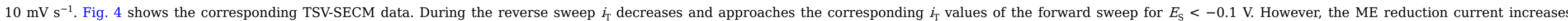

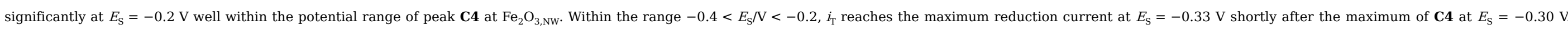

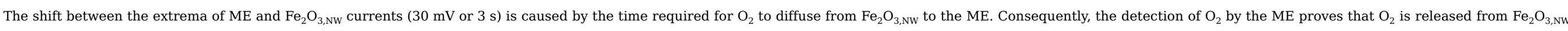

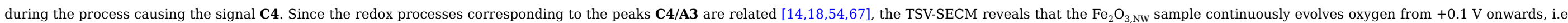

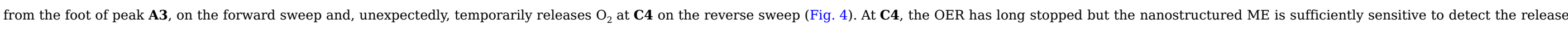

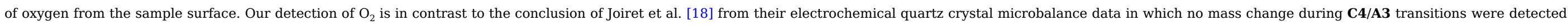

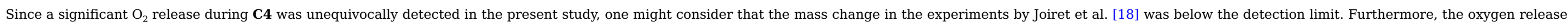

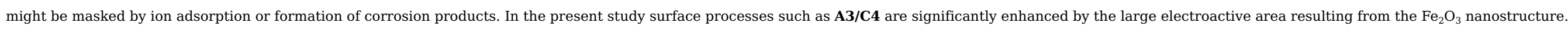




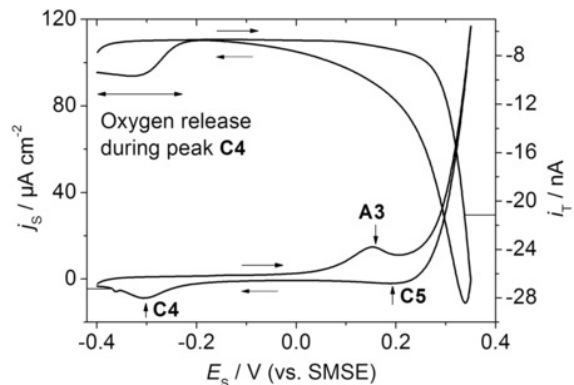

Fig. 4 TSV-SECM of $\mathrm{Fe}_{2} \mathrm{O}_{3, \mathrm{NW}}$ in $0.1 \mathrm{M} \mathrm{NaOH}$ with $E_{\mathrm{T}}=-1.0 \mathrm{~V}$ vs. SMSE, $d=10 \mu \mathrm{m}$ and $v=10 \mathrm{mV} \mathrm{s}^{-1}$.

\section{alt-text: Fig. 4}

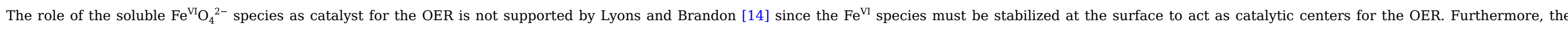

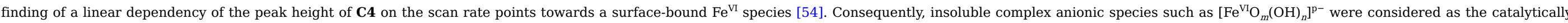

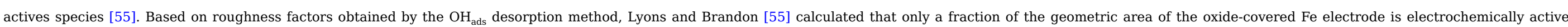

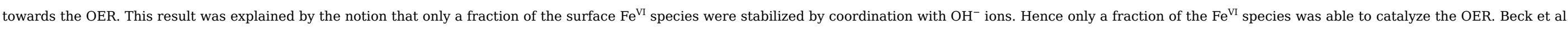
[54] also distinguished between the $\mathrm{Fe}^{\mathrm{VI}} \mathrm{O}_{4}{ }^{2-}$ in solution and their analogous surface species (formally written as $\mathrm{Fe}^{\mathrm{VI}} \mathrm{O}_{3}$, Table $1, \mathbf{A 3} / \mathbf{C 4}$ ).

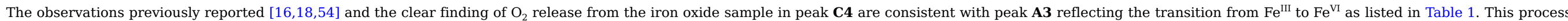
can be represented with the scheme shown below.

Peak A3

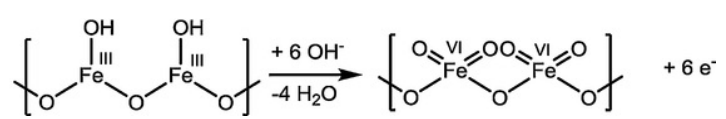

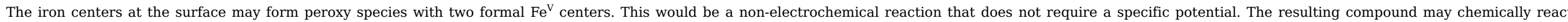

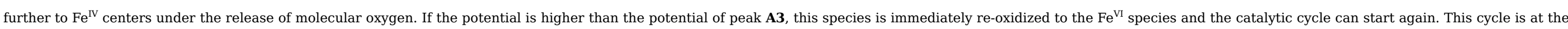

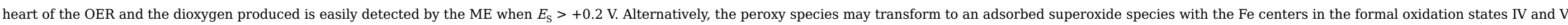
This reaction is independent of potential. The species will remain on the surface as long as the potential is below that of peak $\mathbf{A} 3$ and above that of peak $\mathbf{C 4}$. The overall process is represented in Scheme 9 .

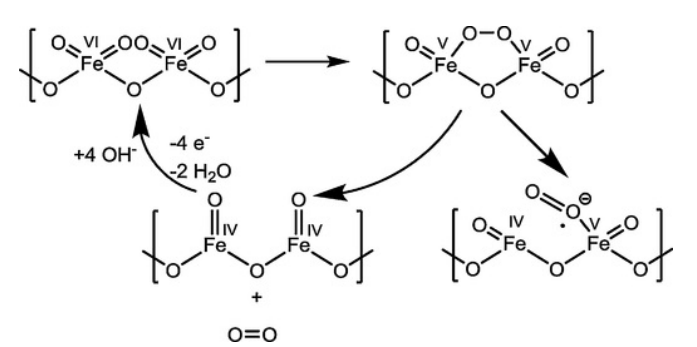

The peak $\mathbf{C 4}$ with the release of molecular oxygen would then be the reduction of the $\mathrm{Fe}^{\mathrm{IV}}-\mathrm{Fe}^{\mathrm{V}}$ centers to $\mathrm{Fe}^{\mathrm{III}}$ - $\mathrm{Fe}^{\mathrm{III}}$ as shown below.

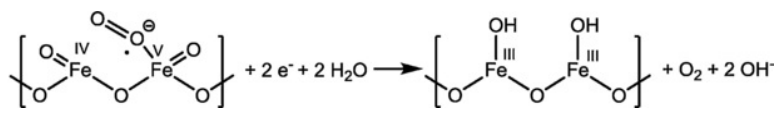

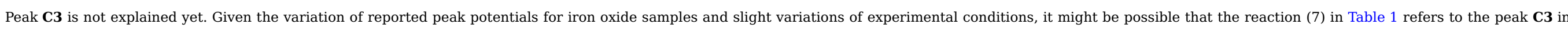
our study and peak $\mathbf{C 4}$ is the reduction with oxygen release (10) that requires a preceding potential-independent surface reaction $(9$, right). 

catalyzes the OER.

\subsection{Hydrogen peroxide formation}

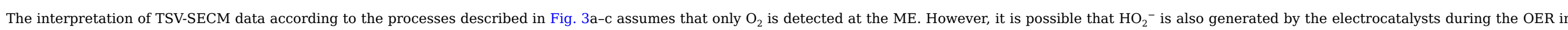

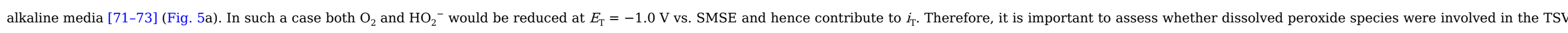

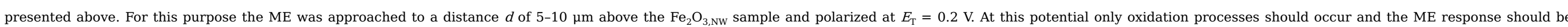

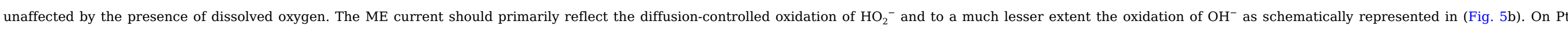

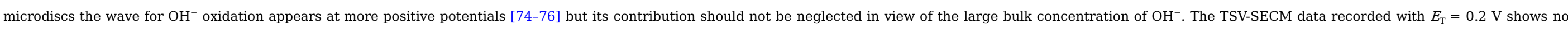

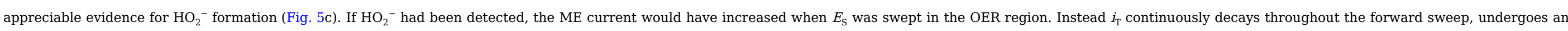

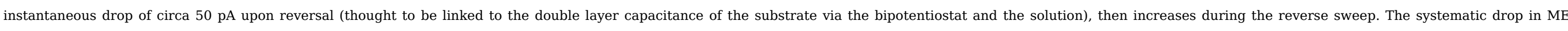

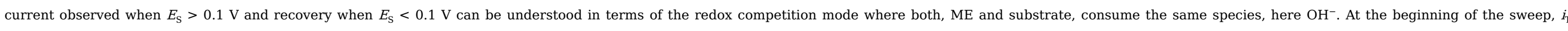

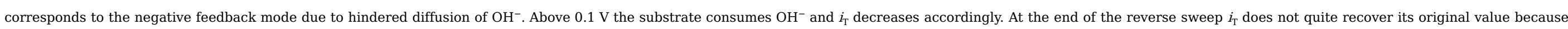

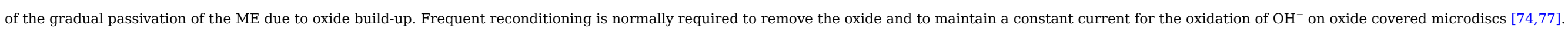

\section{a) $\mathrm{SG} / \mathrm{TC}\left(\mathrm{O}_{2}, \mathrm{HO}_{2}\right) \quad$ b) $\mathrm{SG} / \mathrm{TC}\left(\mathrm{HO}_{2}\right)$}
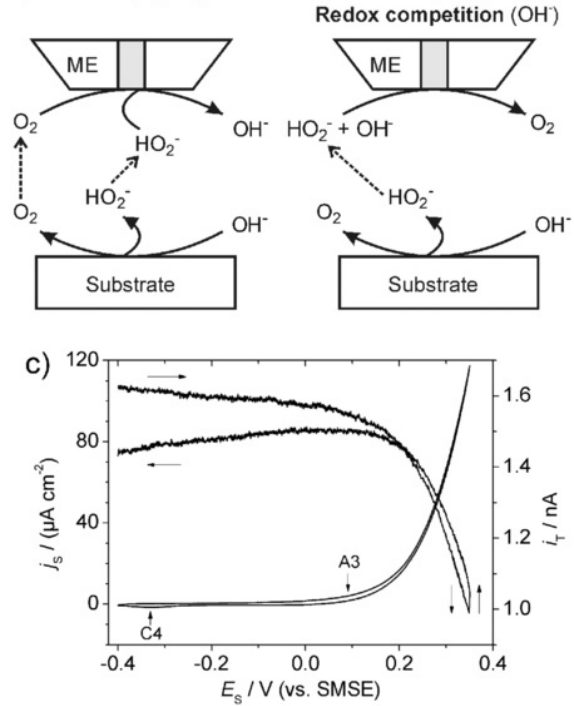

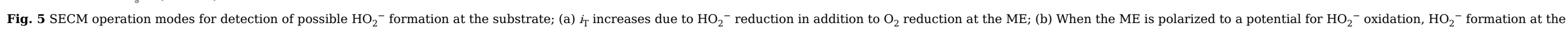
substrate can be unambiguously identified if $\mathrm{H}_{2}$ formation is thermodynamically excluded; (c) TSV-SECM of the $\mathrm{Fe}_{2} \mathrm{O}_{3, \mathrm{NW}}$ in $0.1 \mathrm{M} \mathrm{NaOH}$ with $E_{\mathrm{T}}=0.2 \mathrm{~V}$ vs. SMSE, $d=10 \mu \mathrm{m}$ and $v=10 \mathrm{mV} \mathrm{s}{ }^{-1}$.

alt-text: Fig. 5

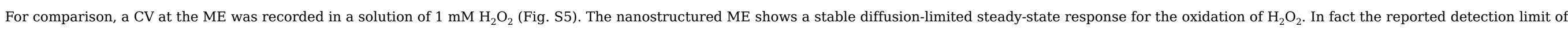

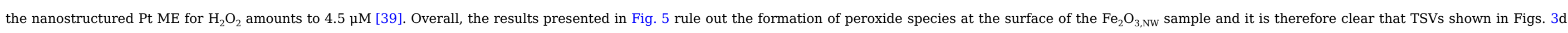
and 4 are solely due to the detection of dissolved oxygen and $\mathrm{HO}_{2}{ }^{-}$does not affect the $\mathrm{ME}$ response for the peak analysis in Section 3.3.

\section{Conclusion}

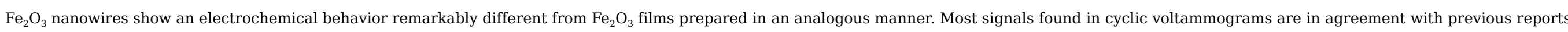




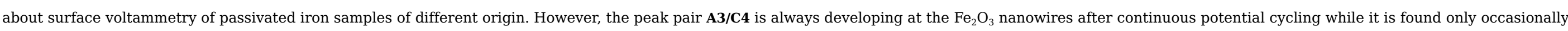

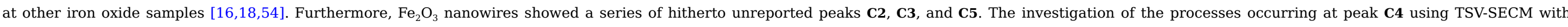

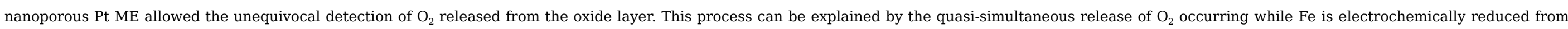
formal oxidation states $\mathrm{Fe}(\mathrm{V})-\mathrm{Fe}(\mathrm{IV})$ to $\mathrm{Fe}(\mathrm{III})-\mathrm{Fe}(\mathrm{III})$, Eq. (10).

\section{Acknowledgments}

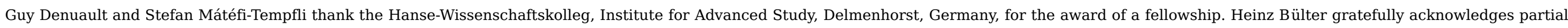
support by the graduate program of Energy Storage and Electromobility (GEENI). The assistance of Andrew Hector and Andreas Lesch is gratefully acknowledged.

\section{Appendix A. Supplementary data}

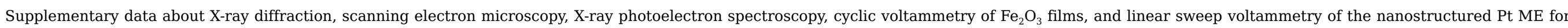
$\mathrm{H}_{2} \mathrm{O}_{2}$ oxidation and reduction in the online version, at http://dx.doi.org/10.1016/j.electacta.2016.11.108.

\section{References}

[1] J. Ohi, Hydrogen energy cycle: An overview, J. Mater. Res. 20, 2005, 3180.

[2] S. Marini, P. Salvi, P. Nelli, R. Pesenti, M. Villa, M. Berrettoni, G. Zangari and Y. Kiros, Advanced alkaline water electrolysis, Electrochim. Acta 82, 2012 , 384.

[3] K. Zeng and D. Zhang, Recent progress in alkaline water electrolysis for hydrogen production and applications, Prog. Energy Combust. Sci. 36, $2010,307$.

[4] D.E. Hall, Nickel hydroxide $\left(\mathrm{Ni}(\mathrm{OH})_{2}\right)$-impregnated anodes for alkaline water electrolysis, J. Electrochem. Soc. 130, $1983,317$.

[5] M.P. Dare-Edwards, J.B. Goodenough, A. Hamnett and P.R. Trevellick, Electrochemistry and photoelectrochemistry of iron(III) oxide, J. Chem. Soc. Faraday Trans. 1 (79), 1983 , 2027.

[6] J.H. Kennedy and K.W. Frese, Jr., Photooxidation of water at $\alpha$-iron(III) oxide electrodes, J. Electrochem. Soc. 125, $1978,709$.

[7] K. Sivula, F. Le Formal and M. Grätzel, Solar Water Splitting: Progress Using Hematite $\left(\hat{\mathrm{I}} \pm \underline{\alpha}-\mathrm{Fe}_{2} \mathrm{O}_{3}\right)$ Photoelectrodes, ChemSusChem 4, $2011,432$.

[8] S.D. Tilley, M. Cornuz, K. Sivula and M. Grätzel, Light-Induced Water Splitting with Hematite: Improved Nanostructure and Iridium Oxide Catalysis, Angew. Chem. Int. Ed. 49, $2010,6405$.

[9] N.T. Hahn and C.B. Mullins, Photoelectrochemical Performance of Nanostructured Ti- and Sn-Doped $\alpha-\mathrm{Fe}_{2} \mathrm{O}_{3}$ Photoanodes, Chem. Mater. 22, 2010 , 6474.

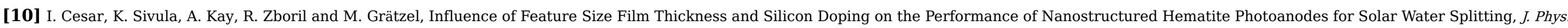
Chem. C 113, 2009, 772.

[11] M. Rioult, H. Magnan, D. Stanescu and A. Barbier, Single Crystalline Hematite Films for Solar Water Splitting: Ti-Doping and Thickness Effects, J. Phys. Chem. C 118, 2014 , 3007.

[12] N. Beermann, L. Vayssieres, S.-E. Lindquist and A. Hagfeldt, Photoelectrochemical studies of oriented nanorod thin films of hematite, J. Electrochem. Soc. 147, $2000,2456$.

[13] S.K. Mohapatra, S.E. John, S. Banerjee and M. Misra, Water photooxidation by smooth and ultrathin $\alpha-\mathrm{Fe}_{2} \mathrm{O}_{3}$ nanotube arrays, Chem. Mater. 21, 2009 , 3048.

[14] M.E.G. Lyons, R.L. Doyle and M.P. Brandon, Redox switching and oxygen evolution at oxidized metal and metal oxide electrodes: iron in base, Phys. Chem. Chem. Phys. 13, $2011,21530$.

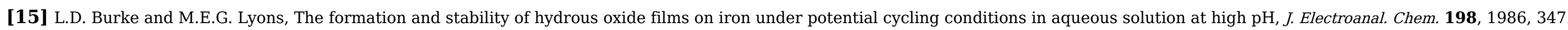

[16] M.E.G. Lyons and M.P. Brandon, Redox switching and oxygen evolution electrocatalysis in polymeric iron oxyhydroxide films, Phys. Chem. Chem. Phys. 11, $2009,2203$.

[17] R.L. Doyle and M.E.G. Lyons, Kinetics and mechanistic aspects of the oxygen evolution reaction at hydrous iron oxide films in base, J. Electrochem. Soc. 160, 2013 , H142.

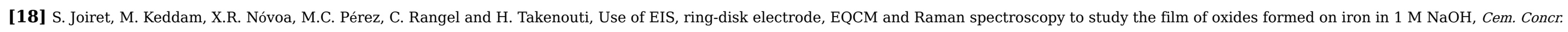


Compos. 24, 2002, 7.

[19] A.J. Bard and M.V. Mirkin, (Eds.), Book Scanning Electrochemical Microscopy, 2012, CRC Press Taylor \& Francis Group Boca Raton; London, New York.

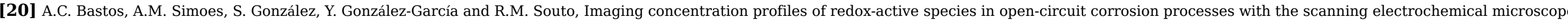
Electrochem. Commun. 6, 2004, 1212.

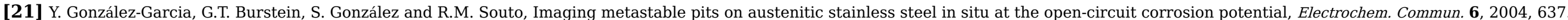

[22] Y. Yin, L. Niu, M. Lu, W. Guo and S. Chen, In situ characterization of localized corrosion of stainless steel by scanning electrochemical microscope, Appl. Surf. Sci. 255, 2009, 9193.

[23] J.W. Still and D.O. Wipf, Breakdown of the iron passive layer by use of the scanning electrochemical microscope, J. Electrochem. Soc. 144, 1997, 2657.

[24] E. Völker, C.G. Inchauspe and E.J. Calvo, Scanning electrochemical microscopy measurement of ferrous ion fluxes during localized corrosion of steel, Electrochem. Commun. 8, 2006, 179.

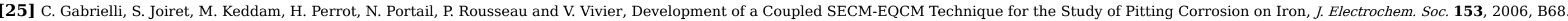

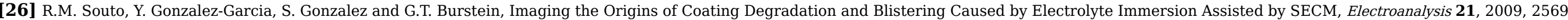

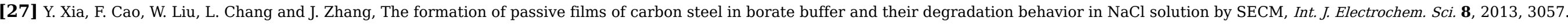

[28] T.E. Lister and P.J. Pinhero, Microelectrode Array Microscopy: Investigation of Dynamic Behavior of Localized Corrosion at Type 304 Stainless Steel Surfaces, Anal. Chem. 77, 2005 , 2601.

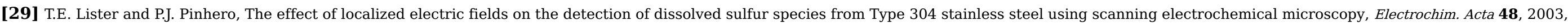
2371

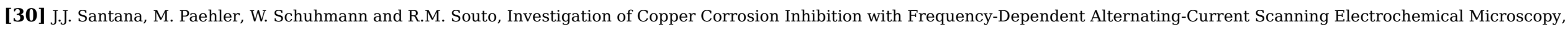
ChemPlusChem 77, 2012, 707.

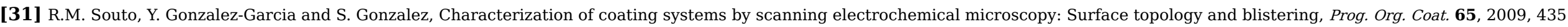

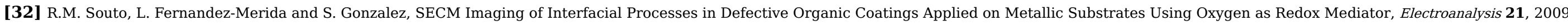
2640

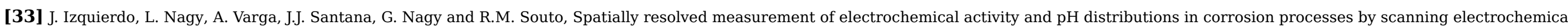
microscopy using antimony microelectrode tips, Electrochim. Acta 56, 2011, 8846.

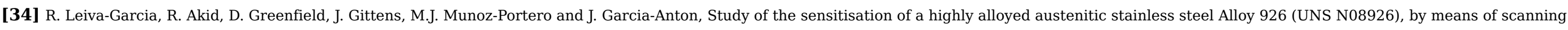
electrochemical microscopy, Electrochim. Acta 70, 2012, 105

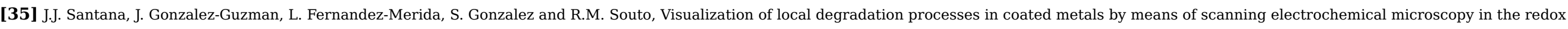
competition mode, Electrochim. Acta 55, 2010, 4488.

[36] J.M. Elliott, P.R. Birkin, P.N. Bartlett and G.S. Attard, Platinum Microelectrodes with Unique High Surface Areas, Langmuir 15, $1999,7411$.

[37] G.S. Attard, P.N. Bartlett, N.R.B. Coleman, J.M. Elliott, J.R. Owen and J.H. Wang, Mesoporous platinum films from lyotropic liquid crystalline phases, Science 278, 1997 , 838.

[38] P.R. Birkin, J.M. Elliott and Y.E. Watson, Electrochemical reduction of oxygen on mesoporous platinum microelectrodes, Chem. Commun. $2000,1693$.

[39] S.A.G. Evans, J.M. Elliott, L.M. Andrews, P.N. Bartlett, P.J. Doyle and G. Denuault, Detection of hydrogen peroxide at mesoporous platinum microelectrodes, Anal. Chem. 74, 2002, 1322.

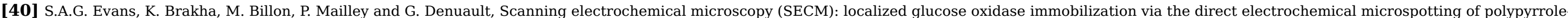


biotin films, Electrochem. Commun. 7, 2005, 135.

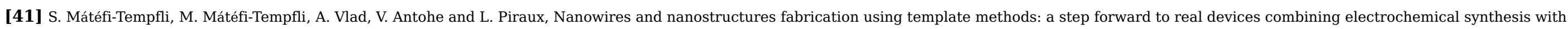
lithographic techniques, J. Mater. Sci.: Mater. Electron. 20, 2009, 249.

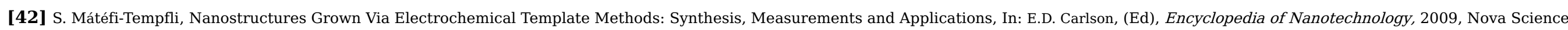
Publishers Inc, 459.

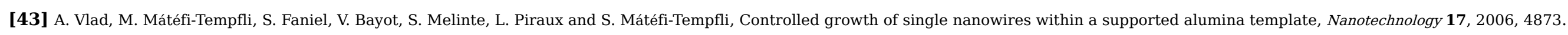

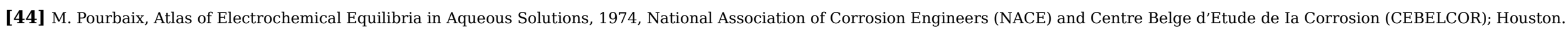

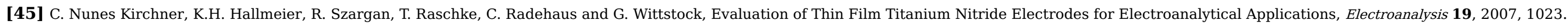

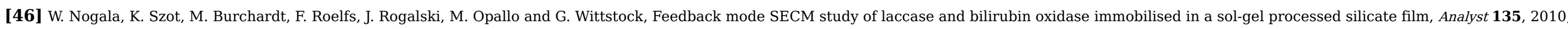
2051.

[47] R. Cornut and C. Lefrou, New analytical approximations for negative feedback currents with a microdisk SECM tip, J. Electroanal. Chem. 608, 2007 , 59.

[48] G. Denuault, M.H.T. Frank and L.M. Peter, Scanning Electrochemical Microscopy: Potentiometric Probing of Ion Fluxes, Faraday Discuss. 94, $1992,23$.

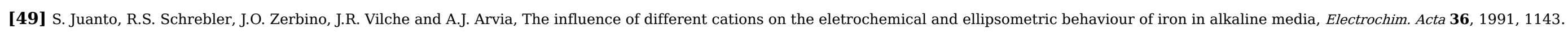

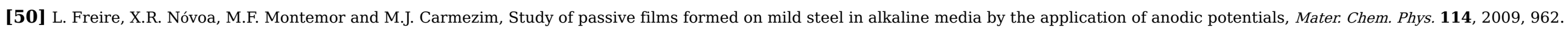

[51] G. Larramona and C. Gutiérrez, The passive film on iron at pH 1-14. A potential-modulated reflectance study, J. Electrochem. Soc. 136, $1989,2171$.

[52] W. Xu, K. Daub, X. Zhang, J.J. Noel, D.W. Shoesmith and J.C. Wren, Oxide formation and conversion on carbon steel in mildly basic solutions, Electrochimica Acta 54, 2009 , 5727.

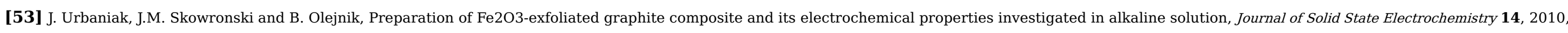
1629.

[54] F. Beck, R. Kaus and M. Oberst, Transpassive dissolution of iron to ferrate(VI) in concentrated alkali [metal] hydroxide solutions, Electrochim. Acta 30, 1985 , 173.

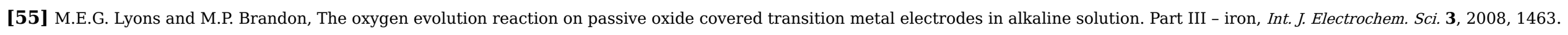

[56] M.E.G. Lyons and M.P. Brandon, A comparative study of the oxygen evolution reaction on oxidized nickel, cobalt and iron electrodes in base, J. Electroanal. Chem. 641, $2010,119$.

[57] R.W. Revie and H.H. Uhlig, Corrosion and Corrosion Control, 2008, Wiley; Hoboken New Jersey.

[58] G. Wulfsberg, Inorganic Chemistry, 2000, University Science Books; Sausalita California.

[59] B. Beverskog and I. Puigdomenech, Revised Pourbaix diagrams for iron at 25-300 ${ }^{\circ} \mathrm{C}$, Corros. Sci. 38, 1996, 2121.

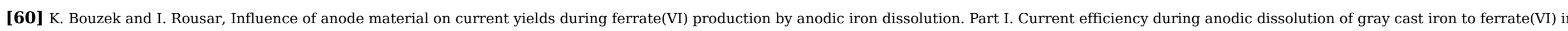
concentrated alkali [metal] hydroxide solutions, J. Appl. Electrochem. 26, 1996, 919.

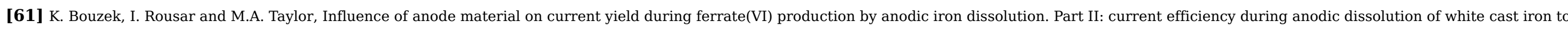
ferrate(VI) in concentrated alkali hydroxide solutions, J. Appl. Electrochem. 26, 1996, 925.

[62] Z. Macova, K. Bouzek, J. Hives, V.K. Sharma, R.J. Terryn and J.C. Baum, Research progress in the electrochemical synthesis of ferrate(VI), Electrochim. Acta 54, $2009,2673$. 
[63] R.H. Wood, The heat, free energy, entropy of the ferrate(VI) ion, J. Am. Chem. Soc. 80, 1958, 2038.

[64] D.G. Lee and H. Gai, Kinetics and mechanism of the oxidation of alcohols by ferrate ion, Can. J. Chem. 71, $1993,1394$.

[65] R.J. Audette, J.W. Quail, W.H. Black and B.E. Robertson, Crystal structures of $\mathrm{M}_{2} \mathrm{FeO}_{4}(\mathrm{M}=$ potassium, rubidium, cesium), J. Solid State Chem. 8, 1973 , 43.

[66] Y.D. Perfiliev and V.K. Sharma, Higher oxidation states of iron in solid state: synthesis and their Mossbauer characterization, ACS Symp. Ser. 985, $2008,112$.

[67] K. Bouzek, I. Rousar, H. Bergmann and K. Hertwig, The cyclic voltammetric study of ferrate(VI) production, J. Electroanal. Chem. 425, 1997, 125.

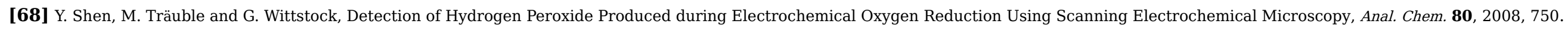

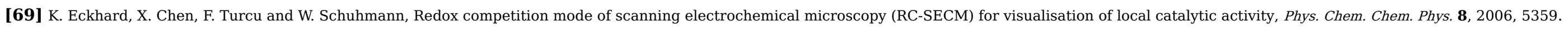

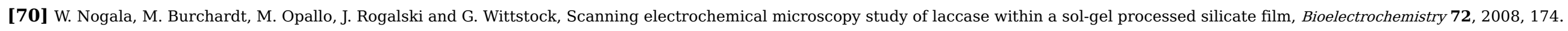

[71] J.O. Bockris and T. Otagawa, The electrocatalysis of oxygen evolution on perovskites, J. Electrochem. Soc. 131, $1984,290$.

[72] P. Paredes Olivera, E.M. Patrito and H. Sellers, Hydrogen peroxide synthesis over metallic catalysts, Surf. Sci. 313, $1994,25$.

[73] K. Juodkazis, J. Juodkazyte, R. Vilkauskaite and V. Jasulaitiene, Nickel surface anodic oxidation and electrocatalysis of oxygen evolution, J. Solid State Electrochem. 12, $2008,1469$.

[74] M.E. Abdelsalam, G. Denuault, M.A. Baldo, C. Bragato and S. Daniele, Detection of Hydroxide Ions in Aqueous Solutions by Steady-State Voltammetry, Electroanalysis 13, $2001,289$.

[75] M.E. Abdelsalam, G. Denuault, M.A. Baldo and S. Daniele, Voltammetry of hydroxide ion in aqueous solutions on gold microelectrodes, J. Electroanal. Chem. 449, $1998,5$.

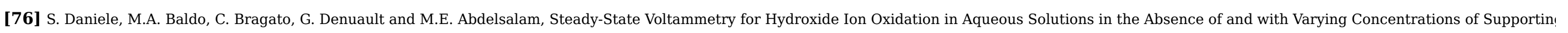
Electrolyte, Anal. Chem. 71, 1999, 811.

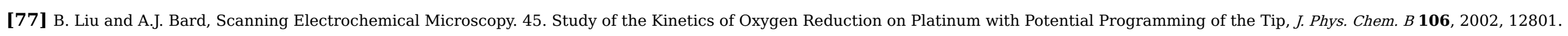

\section{Appendix A. Supplementary data}

The following are Supplementary data to this article:

$\underline{\text { Multimedia Component } 1}$

Graphical abstract

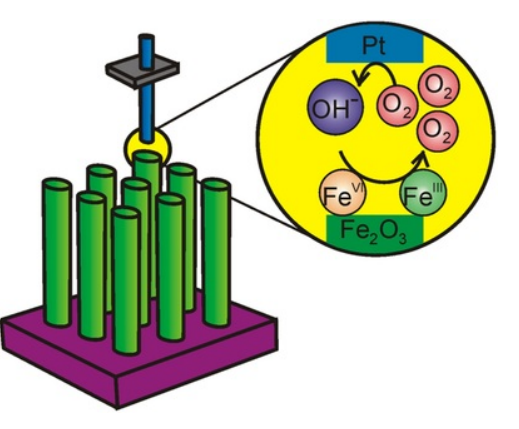


Highlights

- Nanostructured Pt microelectrode as highly sensitive and stable $\mathrm{O}_{2}$ sensor in SECM.

- Identification of new surface redox transitions in nanostructured iron oxide electrodes.

- Identification of $\mathrm{O}_{2}$ released during surface redox transitions in iron oxide thin films. [bullet point] Likely involvement of Fe III/VI redox transition in OER in alkaline solution.

\section{Queries and Answers}

Query: The author names have been tagged as given names and surnames (surnames are highlighted in teal color). Please confirm if they have been identified correctly. Answer: Author surnames are identified correctly

Query: Please check that the affiliations link the authors with their correct departments, institutions, and locations, and correct if necessary.

Answer: institutions are corrected for Dosche

Query: Please check the e-mail addresses for all the authors and correct if necessary.

Answer: email addresses are correct

Query: Please note that two sets of highlights were provided. Therefore, one has been followed. Please check and amend if necessary.

Answer: This was the wrong set of highlights. The most recent must be used.

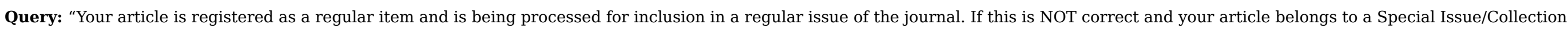
please contact a.elumalai@elsevier.com immediately prior to returning your corrections."

Answer: The article is for a regular issue 